\title{
Tracking the fin trade: genetic stock identification in western Atlantic scalloped hammerhead sharks Sphyrna lewini
}

\author{
Demian D. Chapman ${ }^{1,3}$, Danillo Pinhal ${ }^{1,2}$, Mahmood S. Shivji ${ }^{1, *}$ \\ ${ }^{1}$ Guy Harvey Research Institute and Save Our Seas Shark Center, Oceanographic Center, Nova Southeastern University, \\ 8000 North Ocean Drive, Dania Beach, Florida 33004, USA \\ ${ }^{2}$ Departamento de Morfologia, Instituto de Biociências, Universidade Estadual Paulista, Botucatu, SP, Brazil \\ ${ }^{3}$ Present address: School of Marine and Atmospheric Science \& Institute for Ocean Conservation Science, \\ Stony Brook University, Stony Brook, New York 11794, USA
}

\begin{abstract}
Location or stock-specific landing data are necessary to improve management of shark stocks, especially those imperiled by overexploitation as a result of the international shark fin trade. In the current absence of catch monitoring directly at extraction sites, genetic stock identification of fins collected from major market supply chain endpoints offers an overlooked but potentially useful approach for tracing the fins back to their geographical, or stock of, origin. To demonstrate the feasibility of this approach, we used mitochondrial control region (mtCR) sequences to trace the broad geographical origin of 62 Hong Kong market-derived Sphyrna lewini fins. Of these fins $21 \%$ were derived from the western Atlantic, where this species is listed as 'Endangered' by the International Union for the Conservation of Nature (IUCN). We also show that $S$. lewini mtCR sequences are geographically segregated in the western Atlantic (overall $\Phi_{\mathrm{ST}}=0.74, \mathrm{n}=177$ sharks), indicating that breeding females either remain close to, or home back to, their natal region for parturition. Mixed stock analysis simulations showed that it is possible to estimate the relative contributions of these mitochondrial stocks to fin mixtures in globally sourced trade hubs. These findings underscore the feasibility of using genetic stock identification to source market-derived shark fins to obtain essential and otherwise unavailable data on exploitation levels, and thus to productively inform stock assessment and management of $S$. lewini and potentially also of other fished shark species.
\end{abstract}

KEY WORDS: Wildlife forensics - Provenance - Stock structure - Conservation · Market survey • Mixed stock analysis

Resale or republication not permitted without written consent of the publisher

\section{INTRODUCTION}

Strong demand for shark fins is arguably the major driver of shark mortality globally, with estimates of between 26 and 73 million sharks killed annually to supply the fin markets (Clarke et al. 2006). In the context that most shark fisheries are unregulated, this high level of exploitation is thought to have generated unsustainable fishing pressure on many shark stocks worldwide (Bonfil 1994, Rose 1996, Clarke et al. 2006).

A central goal of most fisheries management and conservation is to manage the resource on a stock- specific basis to preserve the diversity and evolutionary potential of the species as a whole (Dizon et al. 1992). Achieving these stock-specific management goals for sharks has been difficult for several reasons. For one, few shark stocks have been fully delineated using genetic data, even though this is an integral part of stock assessment (FAO 2000, Heist 2005). Another serious problem is that many countries lack the resources, infrastructure, or political will to effectively monitor their shark fishery landings at local extraction sites. Therefore, glaring deficiencies remain in the species and stock-specific catch data required for reliable, 
quantitative shark stock assessments (Bonfil 1994, FAO 2000, ICCAT 2005). In the absence of traditional monitoring at extraction sites, surveying the major market supply chain endpoints has been proposed as a valuable alternative to derive data on species and stock exploitation levels (Clarke et al. 2006, Baker 2008).

Among others, the stocks of the scalloped hammerhead Sphyrna lewini in the western Atlantic are of particular concern. Fins from this mainly coastal, globally distributed, large hammerhead species fetch premium market prices due to their large size and high 'fin needle' content (\$ US 100-120 kg-1; Abercrombie et al. 2005), and this species appears to have collapsed in the western North Atlantic and Gulf of Mexico due to overexploitation (Baum et al. 2003, Myers et al. 2007). Consequently, western Atlantic S. lewini has been listed as 'Endangered' (EN A2bd+4bd) since 2006 on the International Union for the Conservation of Nature's (IUCN) Red List of Threatened Species.

An estimated 1 to 3 million Sphyrna lewini and its congener $S$. zygaena are killed annually worldwide to supply the fin trade (Clarke et al. 2006), but the stockspecific contribution of each species to this total remains unknown. Hammerhead sharks are not currently included on any international management or trade agreements (e.g. CITES), which means that $S$. lewini is primarily assessed and managed under the auspices of domestic fishery regulations or regional fisheries management organizations. This regional level of management underscores the need for geographical origin and/or stock-specific landing data for S. lewini, and indeed for threatened shark species generally.

Genetic stock identification (GSI) methods employ natural spatial partitions in genetic characters to estimate the stock composition of a fishery (Shaklee \& Currens 2003). In vertebrate species where females stay close to, or home back to, their birthplace for parturition or spawning ('natal homing'), the mitochondrial control region (mtCR) locus is often an excellent marker for reconstructing the contribution of distinct spawning, rookery, or nursery regions (hereafter referred to as 'mitochondrial stocks') to fishery catches. GSI using mtCR sequences has been successfully used to source catches of bony fish, sea turtles, and marine mammals back to their stock/birthplace of origin (e.g. Waldman et al. 1996, Laurent et al. 1998, Baker et al. 2000) but has never been applied to sharks.

Given the high market value of fins from Sphyrna lewini and its IUCN Endangered status in the western Atlantic, we wished to determine whether GSI methods could be used to determine whether fins from $S$. lewini originating in this region occurred at detectable frequencies in the contemporary fin market. Findings from a global population genetic study of this species (Duncan et al. 2006) suggest this may be feasible: $S$. lewini mtDNA lineages exhibit strong population structure on a global scale, and no mtCR haplotypes were shared between the Atlantic and the Indian or Pacific oceans, although some Indo-Pacific haplotypes were closely related to Atlantic haplotypes. Correspondingly, the first objective of our study was to determine whether mtCR sequences could be used to trace dried $S$. lewini fins collected in one of the world's largest fin markets (Hong Kong) back to a broad geographical origin.

Western Atlantic stock assessments performed to inform management and conservation efforts require that the stocks being assessed are clearly defined, and also hinge upon the collection of landing and trade data on a finer geographic scale. Duncan et al. (2006) included western Atlantic Sphyrna lewini in their global study, but their sample sizes from this region were too small to examine finer scale stock delineation. Therefore, the second objective of our study was 2fold: (1) to better delineate geographic structuring of $S$. lewini mtDNA lineages within the western Atlantic and (2) to determine whether it would be feasible to use mtCR sequence data to source fins in the market to their natal region of origin on a finer geographic scale within the western Atlantic. Mixed stock analyses (MSA) have been developed for the latter application and carry a level of error that is inversely related to the intensity of stock structure in the species of interest (Waldman et al. 1996, Laurent et al. 1998, Baker et al. 2000, Bowen et al. 2007). We therefore used a simulated MSA to determine whether $S$. lewini mtCR sequences are sufficiently structured in the western Atlantic to permit accurate reconstruction of individual mitochondrial stock contributions to the globally sourced fin mixtures found in major markets.

\section{MATERIALS AND METHODS}

Despite severe sampling constraints associated with limited market access, dried fin samples were obtained from 11 major Hong Kong fin traders (Clarke et al. 2006), and species-specific multiplex PCR confirmed that 62 fins were from Sphyrna lewini (Abercrombie et al. 2005). Steps were taken during sampling to ensure that each fin came from a different animal (e.g. by sampling the same fin position type, e.g. right pectoral at the same trader). DNA was isolated from $\sim 20 \mathrm{mg}$ of each dried fin sample (DNeasy kit, Qiagen). PCR amplification and mtCR sequencing protocols followed Duncan et al. (2006), producing a partial mtCR sequence of $547 \mathrm{bp}$ from the first domain for analysis. Each fin was allocated to a broad geographical origin 
(i.e. western Atlantic, eastern Atlantic, or Indo-Pacific) by matching its haplotype (by eye) to the geographic distribution of mtCR haplotypes obtained from the combined baseline genetic datasets of Duncan et al. (2006), Ovenden et al. (2009), and the present study (combined $\mathrm{n}=452$ wild-caught, globally distributed individuals). The evolutionary relationships of 'novel' market fin haplotypes not recorded in any of these 3 surveys to the known wild-caught haplotypes were assessed using a statistical parsimony network constructed in TCS 4.1 (Clement et al. 2000).

For finer-scale Sphyrna lewini stock delineation within the western Atlantic, we combined the western Atlantic mitochondrial DNA sequences from Duncan et al. (2006) (total $\mathrm{n}=37$; distribution: US Atlantic, $\mathrm{n}=16$; US Gulf of Mexico, $\mathrm{n}=16$; Panama Atlantic, $\mathrm{n}=2$; Brazil, $\mathrm{n}=3$ ) with new sequences that we generated $(n=140)$. We thus analyzed mtCR sequences from a total of 177 wild-caught animals sampled from 4 locations: US Atlantic $(n=53)$, US Gulf of Mexico $(n=45)$, Central American Caribbean (Belize and Panama Atlantic combined; $\mathrm{n}=22$ ), and Brazil $(n=57)$, providing wide coverage of the species' western Atlantic range. DNA isolation and $\mathrm{mtCR}$ sequencing protocols employed for these samples were the same as those used for the market-derived fin samples. Genetic diversity indices were calculated in DnaSP 4.0 (Rozas et al. 2003). Genetic differentiation ( $\Phi_{\mathrm{ST}}$ JukesCantor distances) between the sampling sites and test of their significance was calculated in Arlequin 2.001 (Schneider et al. 2000), using analysis of molecular variance (AMOVA). A statistical parsimony network was constructed for the observed western

Atlantic haplotypes in TCS 4.1 (Clement et al. 2000).

To assess the utility of using MSA for reconstructing individual western Atlantic stock contributions to marketderived mixtures of Sphyrna lewini fins, we ran simulations in a commonly used (e.g. Bowen et al. 2007) MSA program (Statistics Program for Analyzing Mixtures [SPAM 3.7b]; www.cf.adfg. state.ak.us/geninfo/research/genetics/ genetics.php). The SPAM program randomly resampled the baseline mitochondrial haplotype frequency of each western Atlantic mitochondrial stock delineated in this study to construct mixtures ( $\mathrm{n}=100$ animals) with a known (i.e. user-specified) contribution from each stock. The program then uses maximum likelihood (1000 iterations) to reassign each individual in the mixture to its most probable mitochondrial stock of origin and thus reconstruct the contri- bution of each stock to the mixture. The accuracy of future 'blind' (i.e. stock contribution unknown) MSA, given, the level of structure observed, is assessed by the level of concordance obtained between the mean estimated contribution of each mitochondrial stock to the mixture and their known, user-specified contributions. We ran multiple simulations using a wide range of userspecified contributions from each mitochondrial stock (i.e. ranging from equal to various combinations of highly skewed contributions).

\section{RESULTS}

\section{Market fin haplotype composition and relationships}

The 62 Hong Kong market-derived Sphyrna lewini fins were composed of $18 \mathrm{mtCR}$ haplotypes (Table 1). Fifty-seven of these fins matched a known mtCR haplotype from the combined global dataset of Duncan et al. (2006) and the present study (see 'Western Atlantic stock structure'). Of the 5 fins with novel haplotypes, 3 (GenBank accession numbers GU014384, GU014386 and GU014387) had haplotypes very closely related to Indo-Pacific haplotypes (Fig. 1), indicating an IndoPacific origin for these fins. The 2 remaining novel fin haplotypes (accession numbers GU014385 and GU014388) were within 1 substitution of haplotype 13 (West Africa) and haplotype 26 (Caribbean; Fig. 2), respectively, but at least 6 mutational steps from any known Indo-Pacific haplotype, supporting their
Table 1. Sphyrna lewini. Mitochondrial control region (mtCR) haplotypes of 62 dried fins from scalloped hammerhead sharks obtained from the Hong Kong market. Haplotype (HAP 1-26) designations are those used by Duncan et al. (2006). Inferred geographic origin of each haplotype is based on Duncan et al. (2006) and the present study. The NOVEL ATLANTIC and INDO-PACIFIC categories represent haplotypes not yet observed in surveys of wild-caught animals but are closely related to known Atlantic or Indo-Pacific sequences, respectively. NA: not available

\begin{tabular}{|lcc|}
\hline $\begin{array}{l}\text { mtCR haplotype } \\
\text { (no. of fins) }\end{array}$ & Geographic origin & Haplotype source \\
\hline HAP 1 (13) & Indo-Pacific & Duncan et al. (2006) \\
HAP 2 (14) & Indo-Pacific & Duncan et al. (2006) \\
HAP 4 (1) & Indo-Pacific & Duncan et al. (2006) \\
HAP 8 (1) & Indo-Pacific & Duncan et al. (2006) \\
HAP 9 (4) & Indo-Pacific & Duncan et al. (2006) \\
HAP 10 (3) & W Atlantic & Duncan et al. (2006) \\
HAP 12 (3) & W Atlantic (Brazil) & Duncan et al. (2006) \\
HAP 13 (1) & E Atlantic (West Africa) & Duncan et al. (2006) \\
HAP 14 (6) & E Atlantic (West Africa) & Duncan et al. (2006) \\
HAP 15 (4) & W Atlantic (USA, Caribbean, Brazil) & Duncan et al. (2006) \\
HAP 19 (4) & Indo-Pacific & Duncan et al. (2006) \\
HAP 23 (1) & Indo-Pacific & Duncan et al. (2006) \\
HAP 26 (2) & W Atlantic (Caribbean) & Present study \\
2 NOVEL ATLANTIC (2) & NA & Present study \\
3 NOVEL INDO-PACIFIC (3) & NA & Present study \\
\hline \multicolumn{2}{r}{} \\
\hline
\end{tabular}




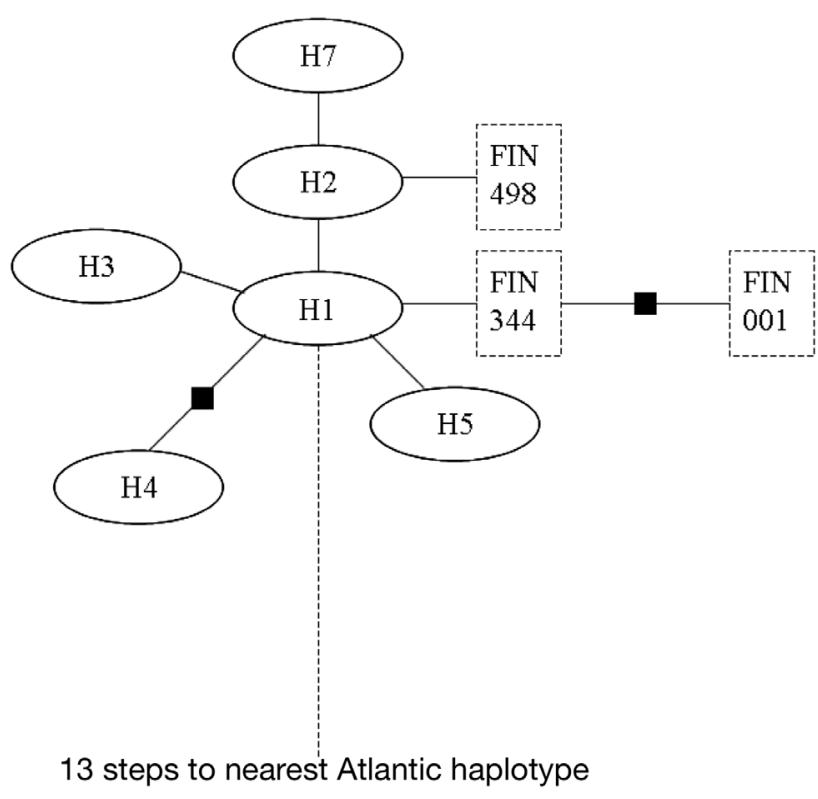

Fig. 1. Sphyrna lewini. Mitochondrial control region (mtCR) haplotype network for scalloped hammerhead sharks sampled in the Indo-Pacific by Duncan et al. (2006), with haplotypes (in ovals) numbered to match their designation in that study. Small squares represent inferred mutational steps. FIN001, FIN498, and FIN344 (dashed boxes) represent 3 Hong Kong market fins with novel haplotypes closely related to the Indo-Pacific haplotypes, but at least 14 mutational steps removed from any known Atlantic haplotype

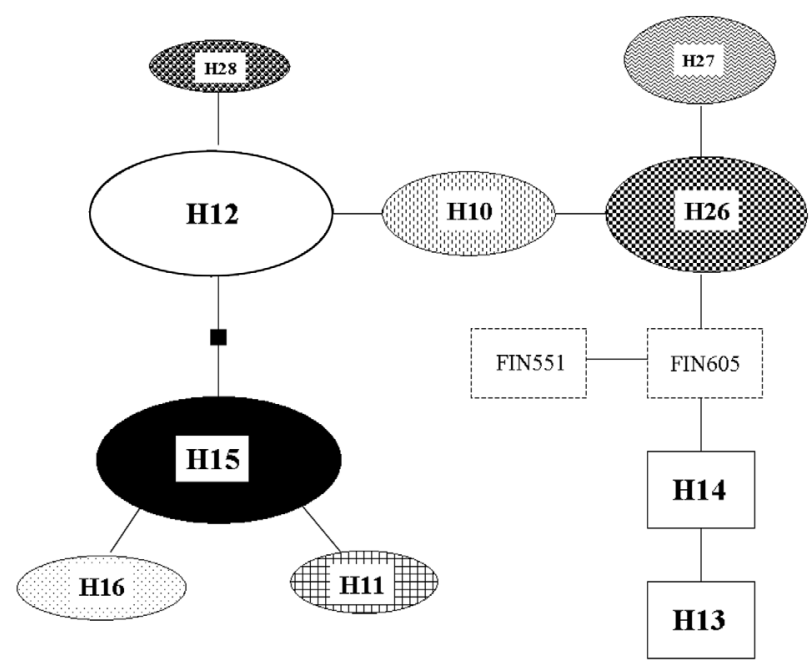

Fig. 2. Sphyrna lewini. MtCR haplotype network for scalloped hammerhead sharks sampled in the western Atlantic. Small square represents an inferred mutational step. Haplotypes H10-16 are numbered according to Duncan et al. (2006); haplotypes H26-28 were discovered in the present study. Haplotypes contained within ovals have been recorded in the western Atlantic, and haplotypes in the solid boxes have only been recorded in the eastern Atlantic. FIN605 and FIN551 (dashed boxes) represent novel, Hong Kong market fin haplotypes that are at least 6 mutational steps from any observed IndoPacific haplotype. Patterns correspond to those used in Fig. 3
Atlantic origin. Thus, all market-derived fins could be traced to capture origins in either the Atlantic or IndoPacific regions (Table 1). Overall, the 62 S. lewini fins originated from the Indo-Pacific ( $65 \%$ ) and both sides of the Atlantic basin (combined total $\sim 34 \%$ ), with a likely $\sim 21 \%$ contribution (13 fins) from the western Atlantic region (Table 1).

\section{Western Atlantic stock structure}

Eight mtCR haplotypes separated by up to 6 mutational steps were found among the 177 wild-caught Sphyrna lewini sampled from the western Atlantic (Fig. 2); 3 of these haplotypes (H26-H28) were novel (i.e. not found in the global survey of Duncan et al. 2006; GenBank accession numbers GU014389, GU014390 and GU014391). None of the western Atlantic haplotypes were recorded in the Indo-Pacific by Duncan et al. $(2006 ; \mathrm{n}=228)$ or Ovenden et al. (2009; $\mathrm{n}=47$ ). Similarly, none of the Indo-Pacific haplotypes were recorded in our survey of western Atlantic animals.

Western Atlantic Sphyrna lewini are structured into at least 3 distinct mitochondrial stocks (overall $\Phi_{\mathrm{ST}}=$ 0.74, p < 0.000001): the 'northern' (comprised of US Atlantic and Gulf of Mexico animals, pairwise $\Phi_{\mathrm{ST}}$ nonsignificant), 'central' (Belize and Panama), and 'southern' (Brazil) stocks (Fig. 3, Table 2). Haplotype and nucleotide diversities were highest in the central mitochondrial stock $(\mathrm{h}=0.731 \pm 0.072 \mathrm{SD}, \pi=0.0035 \pm$ 0.0005 ) and lower in both the northern and southern mitochondrial stocks (northern: US Atlantic and Gulf of Mexico; $h=0.399 \pm 0.06$ and $0.270 \pm 0.02, \pi=0.001 \pm$ 0.0001 and $0.0005 \pm 0.0001$, respectively; southern: $h=$ $0.103 \pm 0.055, \pi=0.0003 \pm 0.0002)$.

\section{MSA}

MSA simulations executed using a range of userspecified stock contributions indicated sufficient structure within the western Atlantic to allow accurate mitochondrial stock-specific landing reconstructions to be made (Table 3). The mean simulationrecovered contributions of each mitochondrial stock were very close to the user-specified contributions with narrow deviation around the mean. This close concordance was true regardless of the degree of skew and relative contributions of the northern, central, or southern Sphyrna lewini mitochondrial stocks used in the mixture (Table 3). We observed haplotypes typical of each stock in the 13 fins that were collected in the Hong Kong market and that originated in the western Atlantic (Table 1). 


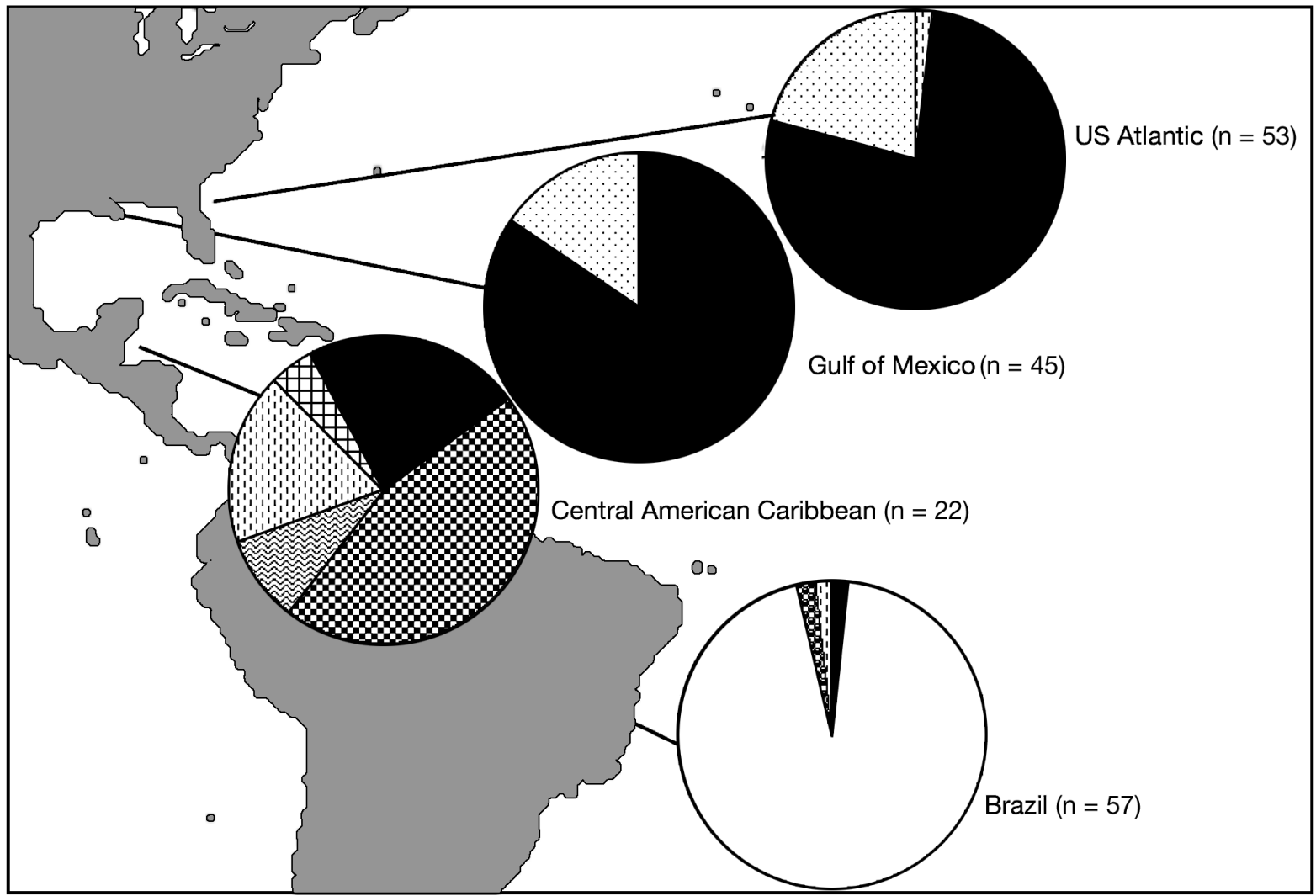

Fig. 3. Sphyrna lewini. mtCR haplotype frequencies of western Atlantic scalloped hammerhead sharks sampled in the US Atlantic (US Atl), US Gulf of Mexico (Gulf of Mex), Central American Caribbean, and Brazil. Haplotypes are pattern-coded to match the haplotype network in Fig. 2 (e.g. haplotype 15 is denoted by the black slices in each pie chart and in Fig. 2)

Table 2. Sphyrna lewini. Population differentiation among western Atlantic scalloped hammerhead sharks collected in 4 regions: US Atlantic (USATL, $n=53$ ), US Gulf of Mexico (USGOM, $\mathrm{n}=45)$, Central American Caribbean (CACAR [Belize and Panama], $\mathrm{n}=22)$, and Brazil $(\mathrm{n}=57)$. Numbers above the diagonal show average pairwise nucleotide divergence between populations (Jukes-Cantor distance). Numbers below the diagonal show pairwise $\Phi_{\mathrm{ST}}$ between populations, with values significantly different from 0 in bold ( $p<0.000001)$. Only the USATL-USGOM pairwise $\Phi_{\mathrm{ST}}$ was not significantly different from $0(\mathrm{p}>0.62)$

\begin{tabular}{|lcccc|}
\hline & USATL & USGOM & CACAR & Brazil \\
\hline USATL & - & 0.00073 & 0.00515 & 0.00410 \\
USGOM & -0.01 & - & 0.00525 & 0.00396 \\
CACAR & $\mathbf{0 . 6 8}$ & $\mathbf{0 . 6 9}$ & - & 0.00364 \\
Brazil & $\mathbf{0 . 8 8}$ & $\mathbf{0 . 9 1}$ & $\mathbf{0 . 6 2}$ & - \\
\hline
\end{tabular}

\section{DISCUSSION}

\section{Market fin provenance}

Our survey of a reasonably large and broadly distributed sample of wild-caught western Atlantic Sphyrna lewini showed no sharing of haplotypes between the
Table 3. Sphyrna lewini. Mixed stock analysis simulation results comparing the concordance between known, userspecified mitochondrial stock contributions and mean reconstructed mitochondrial stock contributions based on stockspecific haplotype frequencies observed in this study. $\mathrm{N}$ : northern stock, C: central stock, S: southern stock (see 'Results' for geographic delineations of stocks)

\begin{tabular}{ll}
$\begin{array}{l}\text { User-specified } \\
\text { contributions }(\%)\end{array}$ & $\begin{array}{l}\text { Reconstructed } \\
\text { contributions (mean } \pm \mathrm{SD}, \%)\end{array}$ \\
\hline $33 \mathrm{~N}, 33 \mathrm{C}, 33 \mathrm{~S}$ & $33.2 \pm 5.7 \mathrm{~N}, 33.4 \pm 5.9 \mathrm{C}, 33.6 \pm 4.9 \mathrm{~S}$ \\
$90 \mathrm{~N}, 5 \mathrm{C}, 5 \mathrm{~S}$ & $90.0 \pm 3.2 \mathrm{~N}, 4.97 \pm 2.5 \mathrm{C}, 4.98 \pm 2.2 \mathrm{~S}$ \\
$5 \mathrm{~N}, 90 \mathrm{C}, 5 \mathrm{~S}$ & $4.90 \pm 4.1 \mathrm{~N}, 90.1 \pm 4.7 \mathrm{C}, 5.1 \pm 2.2 \mathrm{~S}$ \\
$5 \mathrm{~N}, 5 \mathrm{C}, 90 \mathrm{~S}$ & $5.02 \pm 2.8 \mathrm{~N}, 4.96 \pm 2.5 \mathrm{C}, 90.2 \pm 3.2 \mathrm{~S}$
\end{tabular}

western Atlantic $(n=177)$ and Indo-Pacific $(n=275)$, consistent with the findings of Duncan et al. (2006) based on a smaller $(n=37)$ western Atlantic sample set. This strong signal of ocean basin-based mitochondrial 'endemicity' (or likely near-endemicity) suggests that allocation of most market-derived fins to at least an ocean-basin origin will be reasonably robust. Indeed, we were able to exactly match 57 of the 62 market fins to either an Atlantic or Indo-Pacific haplotype. 
Of note is that 7 market fins, which, according to the records of the Hong Kong trader who supplied them, were directly purchased from a West African source, possessed haplotypes identical to the apparently endemic eastern Atlantic haplotypes found in 6 wildcaught animals sampled there by Duncan et al. (2006). If the non-overlapping haplotype distribution between the eastern and western Atlantic is confirmed after increased sampling efforts in the eastern Atlantic, this would mean the origin of at least a portion of Sphyrna lewini fins in trade might also be unambiguously allocated to either of these regions based on their endemic mtCR signature. The observation of non-shared haplotypes across the Atlantic is consistent with the premise that $S$. lewini movements are limited by deep ocean expanses (Duncan et al. 2006), and that female $S$. lewini show fidelity to parturition areas on their natal side of the North Atlantic, as would be expected based on the primarily coastal nature of this species (www.fishbase.org).

Our small genetic survey of Sphyrna lewini fins from the Hong Kong market revealed that the contemporary trade is sourced from the Indo-Pacific, eastern Atlantic, and western Atlantic basins. Assuming that the regional haplotype endemicity pattern distinguishing eastern and western Atlantic S. lewini is true, western Atlantic sharks remain well represented in the Hong Kong market sample ( 21\% of fins), indicating that the international shark fin trade remains a threat to the endangered populations of this region.

\section{Western Atlantic mitochondrial stock structure}

The high $\Phi_{\mathrm{ST}}$ values (Table 2) between sampling locations demonstrate that Sphyrna lewini mtCR lineages are further structured into at least 3 geographically distinct mitochondrial stocks along the eastern American continental margin. This result contrasts with the global data set findings of Duncan et al. (2006) that $S$. lewini nursery populations linked by continuous coastline exhibit high connectivity. Interestingly, Duncan et al. (2006) noted very little sharing of haplotypes between the eastern US, Panama Atlantic, and Brazil coastlines; however, their sample sizes from these regions were too limited ( $\mathrm{n}=32,2$, and 3, respectively) to detect population differentiation. The pattern of strong mitochondrial stock differentiation that we observed along the western Atlantic coastline means either (1) female $S$. lewini remain close to their natal region of origin or (2) females usually return to their natal region to give birth (natal homing). Mitochondrial stock structure has also been described in several other shark species (Pardini et al. 2001, Keeney et al. 2005, Stow et al. 2006, Schultz et al. 2008, Chabot \& Allen 2009) and may prove to be a common characteristic of coastally oriented sharks in particular.

We note that our finding of strong mitochondrial stock structure in the western Atlantic does not preclude male-mediated gene flow, as has been documented in some other shark species also displaying mitochondrial population differentiation (e.g. Pardini et al. 2001, Keeney et al. 2005, Schultz et al. 2008). A global survey of the geographic distribution of nuclear genetic variation in Sphyrna lewini based on microsatellite markers is currently underway to resolve this issue (T. Daly-Engel pers. comm.). The absence of a nuclear genetic perspective on S. lewini population differentiation in the western Atlantic notwithstanding, determining the relative contribution of each mitochondrial stock to fishery landings and international trade is still valuable. Each mitochondrial lineage represents a discrete pool of birthing females and as such can be used to track the natal stock of origin for products in trade to improve management and conservation practice (e.g. Waldman et al. 1996, Laurent et al. 1998, Baker et al. 2000).

The strong signal of mitochondrial stock structure along the western Atlantic coastline is somewhat surprising given the lack of obvious physical barriers (e.g. deep ocean expanses) to a large mobile animal, and the contrasting high mitochondrial connectivity seen along continental margins in Indo-Pacific conspecifics (Duncan et al. 2006). However, a generally similar structuring of mtDNA lineages in the western Atlantic has been observed in other large, mobile marine vertebrates (e.g. manatees, Garcia-Rodriguez et al. 1998; blacktip sharks, Keeney et al. 2005). In the absence of impermeable physical barriers to female-mediated gene flow, it is possible that reproductive season mismatches at different latitudes or local adaptation of individuals to either tropical or warm temperate conditions may inhibit female movements or favor natal homing in these species.

Our assessment of mtCR diversity in Sphyrna lewini from the western Atlantic revealed relatively few haplotypes separated by a small number of mutational steps (Fig. 2), resulting in low haplotype and nucleotide diversities within each region. However, this low mtCR diversity may not be a function of overexploitation, as this pattern was also typical for $S$. lewini sampled from throughout its global range (Duncan et al. 2006). The central stock from the western Atlantic exhibited haplotype and nucleotide diversity comparable to the most diverse Indo-Pacific mitochondrial stocks examined by Duncan et al. (2006), while the northern and southern mitochondrial stocks were intermediate and among the lowest, respectively. 
Adult females are a critical demographic group to protect in order to sustain or rebuild shark populations (Kinney \& Simpfendorfer 2009). The pattern of mitochondrial geographic structure for Sphyrna lewini in the western Atlantic indicates that regional overfishing may potentially deplete locally breeding adult females without significant replenishment of sharks occurring from elsewhere. As such, recovery of the reportedly collapsed S. lewini population in the US Atlantic and northern Gulf of Mexico (Baum et al. 2003, Myers et al. 2007 ) is unlikely to occur by immigration of adult females from the south or across the Atlantic, regardless of male patterns of movement and reproductive mixing. Instead, recovery is likely to depend on an amelioration of local-scale fishing pressure in this region.

\section{MSA}

The proper management of western Atlantic Sphyrna lewini will require information about exploitation levels of adult females using specific regions to breed and individuals derived from the associated nurseries. In this context, results of the MSA simulations provide proof-of-concept that the level of mitochondrial stock structure observed may be sufficient to permit accurate reconstructions of the contribution of each stock to $S$. lewini fin mixtures found in major globally sourced markets. We did not perform MSA on the marketderived, western Atlantic fins identified in this study due to the small sample size $(n=13)$ of fins available. However, the fact that haplotypes typical of each of the 3 mitochondrial stocks were recovered indicates that the contemporary trade of $S$. lewini fins involves the participation of several western Atlantic countries and the exploitation of multiple breeding grounds. These findings underscore the need for investment in stockspecific landings and trade monitoring for a species considered endangered in this region.

Our findings for Sphyrna lewini also suggest that for many other coastal sharks where substantial stock structure is coming to light (e.g. Keeney et al. 2005, Stow et al. 2006, Schultz et al. 2008, Chabot \& Allen 2009), surveying major market supply chain endpoints and applying GSI methods could reveal which regions and stocks are major contributors to the trade. This information is necessary to prioritize target areas for conservation and development of much-needed stockspecific assessment and management measures. Incorporation of additional sampling (more locations, more individuals, and more loci) will allow even more precise assessment of the provenance of shark fishery landings and market products. Until direct monitoring of landings at extraction sites becomes economically and politically realistic, we suggest that genetic monitoring of the market tied to knowledge of stock structure is likely to be a quicker and more efficient way of obtaining these essential data for exploited shark species.

Acknowledgements. We thank D. Abercrombie, M. Grace, L. Knoll, P. Mancini, J. Tyminski, and M. Welch for scalloped hammerhead samples from the western Atlantic. We are especially indebted to S. Clarke for providing fin samples from the Hong Kong market and to D. Abercrombie for laboratory assistance. This research was funded by grants to M.S.S. from the Save Our Seas Foundation, AFTCO, Inc., Florida Sea Grant Program, the Institute for Ocean Conservation Science (founded as the Pew Institute for Ocean Science) and the Hai Stiftung/Shark Foundation. D.D.C. was the recipient of a National Science Foundation predoctoral fellowship and was supported by the Roe Foundation and the Pew Charitable Trusts.

\section{LITERATURE CITED}

Abercrombie DL, Clarke SC, Shivji MS (2005) Global-scale genetic identification of hammerhead sharks: application to assessment of the international fin trade and law enforcement. Conserv Genet 6:775-788

Baker CS (2008) A truer measure of the market: the molecular ecology of fisheries and wildlife trade. Mol Ecol 17: 3985-3998

Baker CS, Lento GM, Cipriano F, Palumbi SR (2000) Predicted decline of protected whales based on molecular genetic monitoring of Japanese and Korean markets. Proc R Soc Lond B Biol Sci 267:1191-1199

Baum JK, Myers RA, Kehler DG, Worm B, Harley SJ, Doherty PA (2003) Collapse and conservation of shark populations in the northwest Atlantic. Science 299:389-392

Bonfil R (1994) Overview of world elasmobranch fisheries. FAO Fish Tech Pap No. 341, Rome

Bowen BW, Grant WS, Hillis-Starr Z, Shaver DJ, Bjorndal A, Bolten AB, Bass AL (2007) Mixed-stock analysis reveals the migrations of juvenile hawksbill turtles (Eretmochelys imbricata) in the Caribbean Sea. Mol Ecol 16:49-60

Chabot CL, Allen LG (2009) Global population structure of the tope (Galeorhinus galeus) inferred by mitochondrial control region sequence data. Mol Ecol 18:545-552

Clarke SC, McAllister MK, Milner-Gulland EJ, Kirkwood GP and others (2006) Global estimates of shark catches using trade records from commercial markets. Ecol Lett 9: 1115-1126

Clement M, Posada D, Crandall KA (2000) TCS: a computer program to estimate gene genealogies. Mol Ecol 9: $1657-1660$

Dizon AE, Lockyer C, Perrin WF, DeMaster DP, Sisson J (1992) Rethinking the stock concept: a phylogeographic approach. Conserv Biol 6:24-36

> Duncan KM, Martin AP, Bowen BW, de Couet DH (2006) Global phylogeography of the scalloped hammerhead shark (Sphyrna lewini). Mol Ecol 15:2239-2251

FAO (United Nations Food and Agriculture Organization) (2000) Fisheries management: 1. Conservation and management of sharks. FAO Technical Guidelines for Responsible Fisheries 4 (Suppl 1), FAO, Rome

> Garcia-Rodriguez AI, Bowen BW, Domning D, MignucciGiannoni AA and others (1998) Phylogeography of the 
West Indian manatee (Trichechus manatus): How many populations and how many taxa? Mol Ecol 7:1137-1149

Heist EJ (2005) Genetics: stock identification. In: Musick JA, Bonfil R (eds) Management techniques for elasmobranch fisheries. FAO Fish Tech Pap 474. United Nations Food and Agriculture Organization, Rome, p 62-75

ICCAT (International Commission for the Conservation of Atlantic Tunas) (2005) Report of the 2004 inter-sessional meeting of the ICCAT subcommittee on by-catches: shark stock assessment. Collect Vol Sci Pap ICCAT 58:799-890

Keeney DB, Heupel MR, Hueter RE, Heist EJ (2005) Microsatellite and mitochondrial DNA analyses of the genetic structure of blacktip shark (Carcharhinus limbatus) nurseries in the northwestern Atlantic. Mol Ecol 14:1911-1923

Kinney MJ, Simpfendorfer CA (2009) Reassessing the value of nursery areas to shark conservation and management. Conserv Lett 2:53-60

Laurent L, Casale P, Bradai M, Godley B and others (1998) Molecular resolution of marine turtle stock composition in fishery bycatch: a case study in the Mediterranean. Mol Ecol 7:1529-1542

Myers RA, Baum JK, Shepherd TD, Powers SP, Peterson CH (2007) Cascading effects of the loss of apex predatory sharks from a coastal ocean. Science 315:1846-1850

Ovenden JR, Kashiwagi T, Broderick D, Giles J, Salini J (2009) The extent of population genetic subdivision differs among four co-distributed shark species in the Indo-Australian archipelago. BMC Evol Biol 9:40

Editorial responsibility: Mike Bruford, Cardiff, UK
Pardini AT, Jones CS, Noble LR, Kreiser B and others (2001) Sex-biased dispersal of great white sharks. Nature 412: 139-140

Rose DA (1996) Shark fisheries and trade in the Americas, Vol 1: North America. TRAFFIC, Cambridge

> Rozas J, Sanchez-DelBarrio JC, Messeguer X, Rozas R (2003) DnaSP, DNA polymorphism analyses by the coalescent and other approaches. Bioinformatics 19:2496-2497

Schneider S, Roessli D, Excoffier L (2000) ARLEQUIN version 2.001: software for population genetic data analysis. Genetics and Biometry Laboratory, Department of Anthropology, University of Geneva

Schultz JK, Feldheim KA, Gruber SH, Ashley MV, Mcgovern TM, Bowen BW (2008) Global phylogeography and seascape genetics of the lemon sharks (genus Negaprion). Mol Ecol 17:5336-5348

Shaklee JB, Currens KP (2003) Genetic stock identification and risk assessment. In: Hallerman EM (ed) Population genetics: principles and applications for fisheries scientists. American Fisheries Society, Bethesda, MD, p 291-328

> Stow A, Zenger K, Briscoe D, Gillings M, Peddemors V, Otway N, Harcourt R (2006) Isolation and genetic diversity of endangered grey nurse shark (Carcharias taurus) populations. Biol Lett 2:308-311

Waldman JR, Hart JT, Wirgin I (1996) Stock composition of the New York Bight Atlantic sturgeon fishery based on analysis of mitochondrial DNA. Trans Am Fish Soc 125: $364-371$

Submitted: April 22, 2009; Accepted: October 1, 2009

Proofs received from author(s): November 27, 2009 